\title{
Japan-US bilateral commodity-level trade and trade policy-related uncertainty under the COVID-19 pandemic: the nonlinear ARDL model
}

\author{
Serdar Ongan ${ }^{1}$ (D) $\cdot$ Ismet Gocer ${ }^{2}$
}

Received: 7 March 2021 / Accepted: 3 September 2021 / Published online: 13 September 2021

(c) The Author(s), under exclusive licence to Springer Science+Business Media, LLC, part of Springer Nature 2021

\begin{abstract}
This study examines whether trade policy-related uncertainties, scaled by TPU index, and the COVID-19 pandemic affect Japan's bilateral commodity trade balance with the U.S concerning 60 industries. To this end, the nonlinear ARDL (autoregressive distributed lag) model is applied. Empirical findings of the disaggregated data model indicate that while changes in Japan's TPU index have significant, either improving or worsening, impacts on this balance concerning 23 industries, changes in US TPU index have impact on only 32 industries. Additionally, based on the behaviors of Japanese and US consumers through their import demands, it can be interpreted that neither of them is uncertainty-sensitive to each other's products and they continue to buy these products even if both countries' TPU indexes keep rising. Another expected empirical finding is that the COVID-19 pandemic worsens the trade balances of Japan for different industries shown in the tables.
\end{abstract}

Keywords TPU index · Nonlinear ARDL approach · Japan · The USA · Trade balances

JEL Classifications F10 · F14 · Q27

\section{Introduction}

Recent retaliatory tariff hikes-wars between the US and Chinese governments have not only affected the bilateral trade flows of these two countries, but also the world's multi-bilateral trade flows. Another impact of these wars and protectionist trade

Serdar Ongan

serdarongan@usf.edu

1 Department of Economics, University of South Florida, Tampa, USA

2 Department of Econometrics, Adnan Menderes University, Aydın, Turkey 
policies is that trade policy-related uncertainties (henceforth, TPU), scaled by the TPU index, have drastically increased. For instance, these indexes in the U.S and Japan, as our sample countries of this study, have increased by $1153 \%$ and $290 \%$, respectively, between August 2016-2019 (Census 2020). In this context, firstly, we seek the answer to a crucial question as to whether the changes in the TPU indexes impact Japan's bilateral trade balance with its top partner, namely the U.S. which totaled at $\$ 219$ billion in two ways in 2019 (Census 2020). If so, secondly, as to whether this impact on this balance is symmetric (linear) or asymmetric (nonlinear). The answer to this question technically will require a decomposition process of the TPU index as $T P U^{+}$and $T P U^{-}$, which corresponds to increases (+) and decreases $(-)$ in this index. Detailed technical instruction about symmetry, asymmetry, and the decomposition process will be explained in the empirical methodology section. It should be noted that this study does not specifically test the impacts of increasing TPU indexes related to US-China trade policy tension in 2018 and U.S withdrawal from the Trans-Pacific Partnership in 2017, but, rather, it tests this in a longer period 1996M1-2021M5, which, of course, includes these two significant years.

To construct ${ }^{1}$ the TPU index, leading national newspapers' coverages are used. Some predetermined words which may correspond to the uncertainties in trade policies are scanned-counted and scaled using a weighting process. These words include the following: trade treaty, trade agreement, tariffs, trade policy, uncertainty, policy, economy, central banks, monetary policies, etc. US and Japan's TPU indexes were created by Caldara et al. (2020) and Arbatli et al. (2019), respectively. Some such main newspapers scanned are Yomiuri, Asahi, Mainichi and Nikkei for Japan and USA Today, Washington Post, Los Angeles Times, New York Times for the U.S. The construction methodology for the TPU index consists of the following steps: (1): Scanning the (aforementioned) words in the newspapers; (2): Getting raw word counts; (3): Scaling the raw word count by the counts of all words; (4): Standardizing each newspaper's series of scaled TPU word counts; (5): Taking a monthly newspaper average to get the TPU index; (6): Multiplicatively normalizing the TPU index to 100 .

It should be noted that the TPU index, as a categorical version of the EPU ${ }^{2}$ (economic policy uncertainty) index by Baker et al. (2016), also gives references to trade policy uncertainties with additional scanned words in trade policy literature. Therefore, we can speculate that changes-shocks in trade flows related to trade policy uncertainties can be better/more thoroughly explained by the TPU index rather than by the EPU index. Hence, the TPU index seems to be a unique independent variable in trade models as compared to the EPU index.

The rest of this study is structured as follows: Sects. 2 provides a literature review, and Sect. 3 explains and provides the empirical methodology and data set. Section 4 provides empirical findings, and Sect. 5 presents the conclusion.

\footnotetext{
${ }^{1}$ For the detailed technical methodology, refer Davis et al. (2019), Baker et al. (2016), Caldara et al. (2020), Arbatli et al. (2019), Čižmešija et al. (2017).

${ }^{2}$ For the detailed technical methodology, refer Baker et al. (2016).
} 


\section{Literature review}

The EPU index was widely used in many empirical studies to investigate the impacts of economic policy-related uncertainties on different micro-macroeconomic levels of variables, such as foreign direct investments (Hsieh et al. 2019; Canh et al. 2020), exchange rates (Beckmann and Czudaj 2017; Liming et al. 2020), Bitcoin prices (Demir et al. 2018; Wang et al. 2020), interest rates (Ashraf and Shen 2019), GDP (Ghirelli et al. 2019; Huang and Luk 2020), stock returns (Li et al. 2015; Yin et al. 2017; Chen and Chiang 2020) and demand for money (Ivanovski and Churchill 2019; BahmaniOskoosee and Nayeri 2020). However, the impacts of the EPU index on global-national level trade flows were not examined as much as the macroeconomic variables presented above. A few scholars have tested these impacts on trade flows. For instance, Han et al. (2016) applied the global vector autoregressive (GVAR) model for China and found that US and Japan's TPU indexes have negative impacts on China's export. Tam Sun (2018) applied the same methodology for China and the U.S and found that the EPU indexes of these countries have significant effects on global trade flows. Constantinescu et al. (2015) used a panel model for 18 countries and found that an increase in the EPU index significantly reduces the growth of trade flows. Beckmann and Czudaj (2017) applied the vector autoregression (VAR) model for some countries and found that the EPU indexes play determining roles in trade flows transmitted by exchange rates. Shin et al. (2018) applied the VAR model for South Korea and found strong correlations between the EPU index and the current account balance of this country. Wei (2019) used the VAR model for China and found that the global EPU index has negative impacts on Chinese real export. Adedoyin et al. (2020) used the export-led growth hypothesis (ELGH) for Malaysia and found that the EPU index has moderately negative impacts on export flows for this country. Jia et a. (2020) applied a gravity model approach for 20 countries. They found that exports of countries are negatively associated with the EPU indexes. However, unlike the EPU index, very little is known about whether changes in the TPU index affect trade flows in trade models. Therefore, we believe that this study, which uses the TPU index, will bridge this gap in relevant literature.

\section{Empirical methodology and data set}

The empirical methodology of this study consists of two steps. In the first step, we decompose the TPU indexes of both countries into their increases $(+)$ and decreases (-) in the following partial sum process:

$$
\begin{aligned}
& \mathrm{TPU}_{t}^{+}=\sum_{k=1}^{T} \Delta \mathrm{TPU}_{k}^{+}=\sum_{k=1}^{T} \max \left(\Delta\left(\mathrm{TPU}_{k}, 0\right)\right) \\
& \mathrm{TPU}_{t}^{-}=\sum_{k=1}^{T} \Delta \mathrm{TPU}_{k}^{-}=\sum_{k=1}^{T} \min \left(\Delta\left(\mathrm{TPU}_{k}, 0\right)\right)
\end{aligned}
$$


where $\mathrm{TPU}^{+}$and $\mathrm{TPU}^{-}$are partial sums of increases (+) and decreases $(-)$of the TPU indexes. Hence, we obtain the TPU ${ }_{t}^{U S^{+}}, \mathrm{TPU}_{t}^{U S^{-}}$for the U.S and $\mathrm{TPU}_{t}^{J P N^{+}}$, $\mathrm{TPU}_{t}^{J P N^{-}}$for Japan. In the second step, we apply the nonlinear ARDL (autoregressive distributed lag) model of Shin et al. (2014). This model enables us to test the impacts of changing $\mathrm{TPU}_{t}^{U S^{+}}, \mathrm{TPU}_{t}^{U S^{-}}, \mathrm{TPU}_{t}^{J P N^{+}}$, and $\mathrm{TPU}_{t}^{J P N^{-}}$indexes on Japan's bilateral trade balance with the U.S (henceforth, $\mathrm{BTB}_{i t}^{J P N_{-}} t_{S}$ ), separately. Because we assume that each index (series) may affect this balance in different magnitudes and different directions asymmetrically (nonlinearly). For instance, rises in the US TPU index $\left(\mathrm{TPU}_{t}^{U S^{+}}\right.$) may lead to declines in $\mathrm{BTB}_{i t}^{J P N_{-} U S}$ or declines in the US TPU index $\left(\mathrm{TPU}_{t}^{U S^{-}}\right)$may lead to rises in $\mathrm{BTB}_{i t_{-}}^{J P N_{U} U S}$ nonlinearly asymmetrically. Furthermore, the impacts of $\mathrm{TPU}_{t}^{U S^{+}}$on $\mathrm{BTB}_{i t}^{J P N_{-}^{i t} U S}$ can be higher or lower than the impacts of $\mathrm{TPU}_{t}^{U S^{-}}$on it. Symmetry is defined as same magnitude and same direction impacts of TPU indexes on $\mathrm{BTB}_{i t}^{J P N_{-} U S}$. Before forming the nonlinear ARDL model of the study, we, first, present the following regressed basic model with decomposed TPU indexes (variables).

$$
\begin{aligned}
\operatorname{LogBTB}_{i t}^{J P N_{-} U S}= & \beta_{0}+\beta_{1} \operatorname{REXR}_{t}^{J P Y_{-} U S D}+\beta_{2} \log Y_{t}^{J P N}+\beta_{3} \log Y_{t}^{U S}+\beta_{4} \operatorname{LogTPU}_{t}^{J P N^{+}} \\
& +\beta_{5} \operatorname{LogTPU}_{t}^{J P N^{-}}+\beta_{6} \operatorname{LogTPU}_{t}^{U S^{+}}+\beta_{7} \operatorname{LogTPU}_{t}^{U S^{-}}+\beta_{8} D_{\mathrm{Covid}_{t}}+\varepsilon_{t}
\end{aligned}
$$

The variables in the model above are defined as follows:

$\mathrm{BTB}_{i t}^{J P N_{-} U S}$ : Japan's bilateral trade balance with the U.S, defined as the ratio of Japan's imports $(m)$ from the U.S and Japan's exports $(x)$ to the U.S as a ratio of $m / x$. This means that $B T B_{i t}^{J P N_{-} U S}=m / x$. This ratio was proposed by Haynes and Stone (1982) and utilized by Bahmani-Oskoosee and Brooks (1999). Dependent variable of this study is based on the form of bilateral balance which shows the relative strength of a country's trade performance as a whole. Consequently, this form variable can make more sense than taking the variables export and import individually on a country's trade performance.

$\operatorname{REXR}_{t}^{J P Y} U S D$ : the CPI adjusted real exchange rate between the Japanese YEN (JPY) and the USD. It is defined as $\mathrm{REXR}_{t}^{J P Y \_U S D}=\left(\mathrm{NEX}_{t} * \mathrm{CPI}_{t}^{J P N}\right) / \mathrm{CPI}_{t}^{U S}$. NEX is the nominal exchange rate, defined as units of USD per JPY.

$Y_{t}^{J P N}$ and $Y_{t}^{U S}$ : Japan's and U.S income levels scaled by industrial production indexes, respectively

$\mathrm{TPU}_{t}^{J P N^{+}}, \mathrm{TPU}_{t}^{J P N^{-}}, \mathrm{TPU}_{t}^{U S^{+}}$and TPU ${ }_{t}^{U S^{-}}$: increases and decreases in Japan's and US trade policy uncertainty indexes (TPUs), respectively.

$D_{\text {Covid }}$ is the COVID-19 pandemic and defined as a Dummy variable that takes value 1 after February 2020 as the first month for the worldwide pandemic cases recorded.

The expected sign of $\beta_{1}$ is to be positive since depreciations in JPY will improve $\mathrm{BTB}_{i t_{P N} U S}^{J P N_{U}}$. The positive sign here denotes the same direction impact of $\beta_{1}$ on $\mathrm{BTB}_{i t}^{f_{P N} U S}$. The expected signs of $\beta_{2}$ and $\beta_{3}$ are to be positive and negative, respectively. This means that while increases in Japan's income will worsen BTB ${ }_{i t}^{J P N_{-} U S}$ due to increases in Japan's import from the U.S (it denotes same direction impact), increases in US income will improve $\mathrm{BTB}_{i t}^{J P N_{-} U S}$ due to increases in US import from Japan (it denotes different direction impact). Finally, the expected signs of $\beta_{4}, \beta_{5}, \beta_{6}$ 
and $\beta_{7}$ are to be either positive or negative. This means that there is not any specific expectation for them about how they interact with $\mathrm{BTB}_{i t}^{J P N \_U S}$. The expected sign of $\beta_{8}$ is to be positive. This means that increases in COVID-19 cases will worsen.

$\mathrm{BTB}_{i t}^{J P N_{-} U S}$ due to decreases in Japan's export to the U.S. The model of this study was run for both aggregated and disaggregated data, separately. The disaggregated data model includes 60 (3-digits) industrial commodities traded between Japan and the U.S. The rationale of using disaggregated data is to avoid aggregation biases, which can cause misleading results. This means that disaggregated data can discover potentially concealed yet existing relationships between dependent and independent variables, which the aggregated data model cannot detect. Monthly commodity flows were obtained from the US Census Bureau. The nominal exchange rates, CPIs and GDPs series were obtained from the Federal Reserve Bank of St. Louis. The TPU index series of the US and Japan were obtained from https://www. policyuncertainty.com. The sample period is 1996M1-2021M5.

Following the basic model in Eq. 3, we apply the nonlinear ARDL model for both aggregated and disaggregated data in Eq. 4. The advantage of using this nonlinear model is that it is applicable regardless of whether the underlying regressors are I(0), purely I(1) or mutually cointegrated (Pesaran and Pesaran, 1997).

$$
\begin{aligned}
\Delta \mathrm{LogBTB}_{i t}^{J P N_{-} U S}= & \beta_{0}+\beta_{1} \operatorname{LogBTB}_{i t-1}^{J P N_{-} U S}+\beta_{2} \mathrm{REXR}_{t-1}^{J P Y_{-} U S D}+\beta_{3} \log Y_{t-1}^{J P N}+\beta_{4} \log Y_{t-1}^{U S}+\beta_{5} \operatorname{LogTPU}_{t-1}^{J P N^{+}} \\
& +\beta_{6} \operatorname{LogTPU}_{t-1}^{J P N^{-}}+\beta_{7} \operatorname{LogTPU}_{t-1}^{U S^{+}}+\beta_{8} \operatorname{LogTPU}_{t-1}^{U S^{-}}+\beta_{9} D_{\mathrm{Covid}_{t-1}}+\sum_{j=1}^{p_{1}} \beta_{10 j} \Delta \operatorname{LogBTB}_{i t-j}^{J P N_{-} U S} \\
& +\sum_{j=0}^{p_{2}} \beta_{11 j} \Delta \operatorname{REXR}_{t-j}^{J P Y_{-} U S D}+\sum_{j=0}^{p_{3}} \beta_{12 j} \Delta \log Y_{t-j}^{J P N}+\sum_{j=0}^{p_{4}} \beta_{13 j} \Delta \log Y_{t-j}^{U S}+\sum_{j=0}^{p_{5}}\left(\beta_{14 j} \Delta \operatorname{LogTPU}_{t-j}^{J P N^{+}}\right. \\
& \left.+\beta_{15 j} \Delta \operatorname{LogTPU}_{t-j}^{J P N^{-}}\right)+\sum_{j=0}^{p_{6}}\left(\beta_{16 j} \Delta \operatorname{LogTPU}_{t-j}^{U S^{+}}+\beta_{17 j} \Delta \operatorname{LogTPU}_{t-j}^{U S^{-}}\right)+\varepsilon_{t}
\end{aligned}
$$

In Eq. 4, we determine the long-run impacts of changes in $\mathrm{TPU}_{t}^{J P N^{+}}, \mathrm{TPU}_{t}^{J P N^{-}}$and $\mathrm{TPU}_{t}^{U S^{+}}, \mathrm{TPU}_{t}^{U S^{-}}$indexes on $\mathrm{BTB}_{i t}^{J P N_{-} U S}$ with the signs and significances of $-\beta_{5} / \beta_{1}$, $-\beta_{6} / \beta_{1}$ and $-\beta_{7} / \beta_{1},-\beta_{8} / \beta_{1}$, respectively.

\section{Empirical findings}

Descriptive statistics of the variables are provided in Table 1.

The low standard deviation indicates that the data of the variables are clustered closely around the mean. Table 2 reports the estimates of normalized long-run coefficients and diagnostics of the nonlinear ARDL model for both aggregated and disaggregated data.

Test results in Table 2 will be evaluated for aggregated and disaggregated (industries) data models, separately. The letters " $W$ " and " $P$ " in this table and text imply that the relevant independent variable in the relevant industry worsens and $i$ mproves $B T B_{i t}^{J P N_{-} U S}$, respectively. Furthermore, the letters " $S$ " and " $A$ " (at last two columns) correspond to symmetry and asymmetry determined by the Wald 
Table 1 Descriptive statistics

\begin{tabular}{lllllllll}
\hline & Total X & Total M & BTB & TPU $^{\text {JPN }}$ & TPU $^{\text {USA }}$ & IPI $^{\text {JPN }}$ & IPI $^{\text {USA }}$ & REX $^{\text {JPY_USD }}$ \\
\hline Mean & $5.70 \mathrm{E}+09$ & $1.20 \mathrm{E}+10$ & 48.13 & 132.58 & 116.40 & 102.72 & 93.50 & 0.01 \\
Median & $5.34 \mathrm{E}+09$ & $1.13 \mathrm{E}+10$ & 47.58 & 83.35 & 57.62 & 102.02 & 94.76 & 0.01 \\
Maximum & $1.20 \mathrm{E}+10$ & $2.55 \mathrm{E}+10$ & 71.59 & 722.30 & 1946.68 & 119.47 & 106.19 & 0.01 \\
Minimum & 4758.542 & 6646.898 & 36.15 & 11.12 & 10.56 & 78.29 & 71.73 & 0.01 \\
Std. Dev & $2.35 \mathrm{E}+09$ & $5.04 \mathrm{E}+09$ & 6.20 & 127.31 & 199.51 & 6.68 & 7.45 & 0.00 \\
Skewness & 0.45 & 0.52 & 0.72 & 2.28 & 4.78 & -0.17 & -0.66 & 0.20 \\
Kurtosis & 4.56 & 4.58 & 3.82 & 8.33 & 33.29 & 4.64 & 3.13 & 1.93 \\
Jarque-Bera & 41.16 & 45.24 & 34.83 & 626.21 & $12,821.20$ & 35.81 & 22.35 & 16.54 \\
Observations & 305 & 305 & 305 & 305 & 305 & 305 & 305 & 305 \\
\hline
\end{tabular}

test. $W_{L R^{T P U_{-} J P N}}$ and $W_{L R^{T P U_{-} U S}}$ are long-run Wald tests of TPU indexes for Japan and the U.S, respectively.

The results of the aggregated data model in Table 2 (in the first row of the table) indicate that depreciations or appreciations $\left(\operatorname{REXR}_{t}^{J P Y}{ }_{-} U S D\right)$ in the JPY against the USD do not impact Japan's bilateral trade balance with the U.S. (BTB ${ }_{i t}^{J P N_{-} U S}$ ) since the coefficient of $\operatorname{REXR}_{t}^{J P Y_{-} U S D}$ is not statistically significant. This can be interpreted as meaning that neither country's consumers, through their import demands, are exchange rate-sensitive to each other's products. While rises in Japan's income $\left(Y_{t}^{J P N}\right)$ do not impact $\mathrm{BTB}_{i t}^{J P N_{-} U S}$, rises in US income $\left(Y_{t}^{U S}\right)$ improve it. This can be interpreted as meaning that US consumers, through their import demands, are income-sensitive to Japanese products and they buy these products while their income levels rise. However, Japanese consumers are not income-sensitive to US products. Test results in Table 2 for the aggregated data model indicate that changes in both countries' TPU indexes have important impacts on $\mathrm{BTB}_{i t}^{J P N_{-} U S}$. While rises in Japan's TPU index $\left(\mathrm{TPU}_{t}^{J P N^{+}}\right.$) worsen $\mathrm{BTB}_{i t}^{J P N_{-} U S}$, falls $\left(\mathrm{TPU}_{t}^{J P N^{-}}\right.$) improve it. Based on the behaviors of Japanese consumers, through import demands, this can be interpreted as meaning that Japanese consumers are not uncertainty-sensitive to US products and they continue to buy such products, while Japan's TPU index rises $\left(\mathrm{TPU}_{t}^{J P N^{+}}\right)$. Similarly, they are uncertainty-sensitive to US products and they reduce their purchases of these products while TPU index falls $\left(\mathrm{TPU}_{t}^{J P N^{-}}\right)$. In regards to changes in the US TPU index, while rises in the US TPU index (TPU ${ }_{t}^{U S^{+}}$) improve $\mathrm{BTB}_{i t}^{J P N_{-} U S}$, falls $\left(\mathrm{TPU}_{t}^{U S^{-}}\right.$) worsen it. Based on the behaviors of US consumers, through their import demands, this can be interpreted as meaning that US consumers are not uncertainty-sensitive to Japanese products and they continue to buy such products while the US TPU index rises (TPU ${ }_{t}{ }^{+}$). Similarly, US consumers are uncertainty-sensitive to Japanese products and they reduce their purchases of these products while the US TPU index falls $\left(\mathrm{TPU}_{t}^{U S^{-}}\right)$. Aggregated data model finds no impacts of the COVID-19 on $\mathrm{BTB}_{i t}^{J P N_{-} U S}$ since the coefficient of $L_{D_{\text {Covid }}}$ is insignificant.

Empirical results of the disaggregated data model (industries) are totally different than empirical results of the aggregated data model. While aggregated data model finds no impacts of exchange rate on $\mathrm{BTB}_{i t}^{J P N \_U S}$, the disaggregated data 


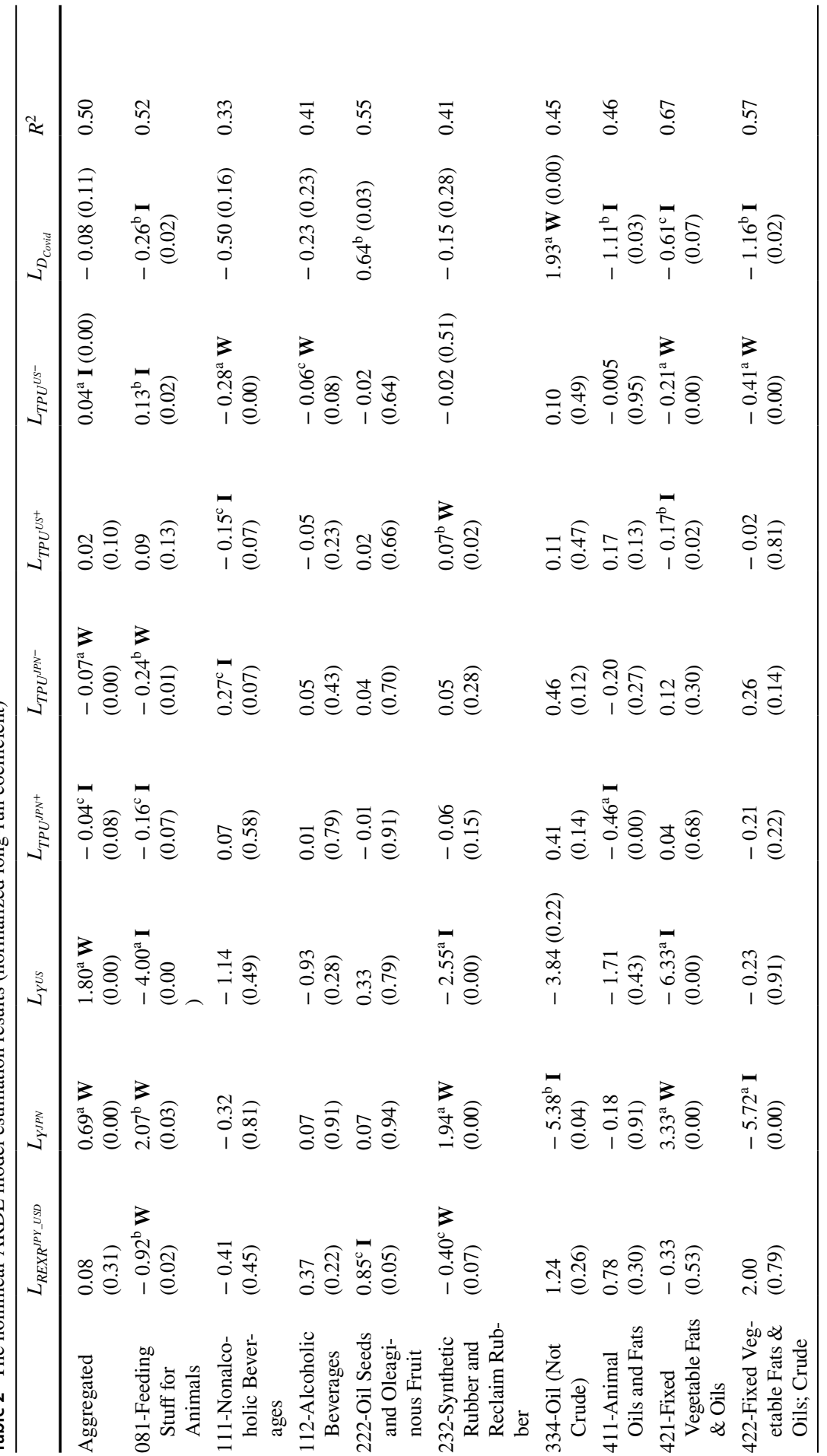




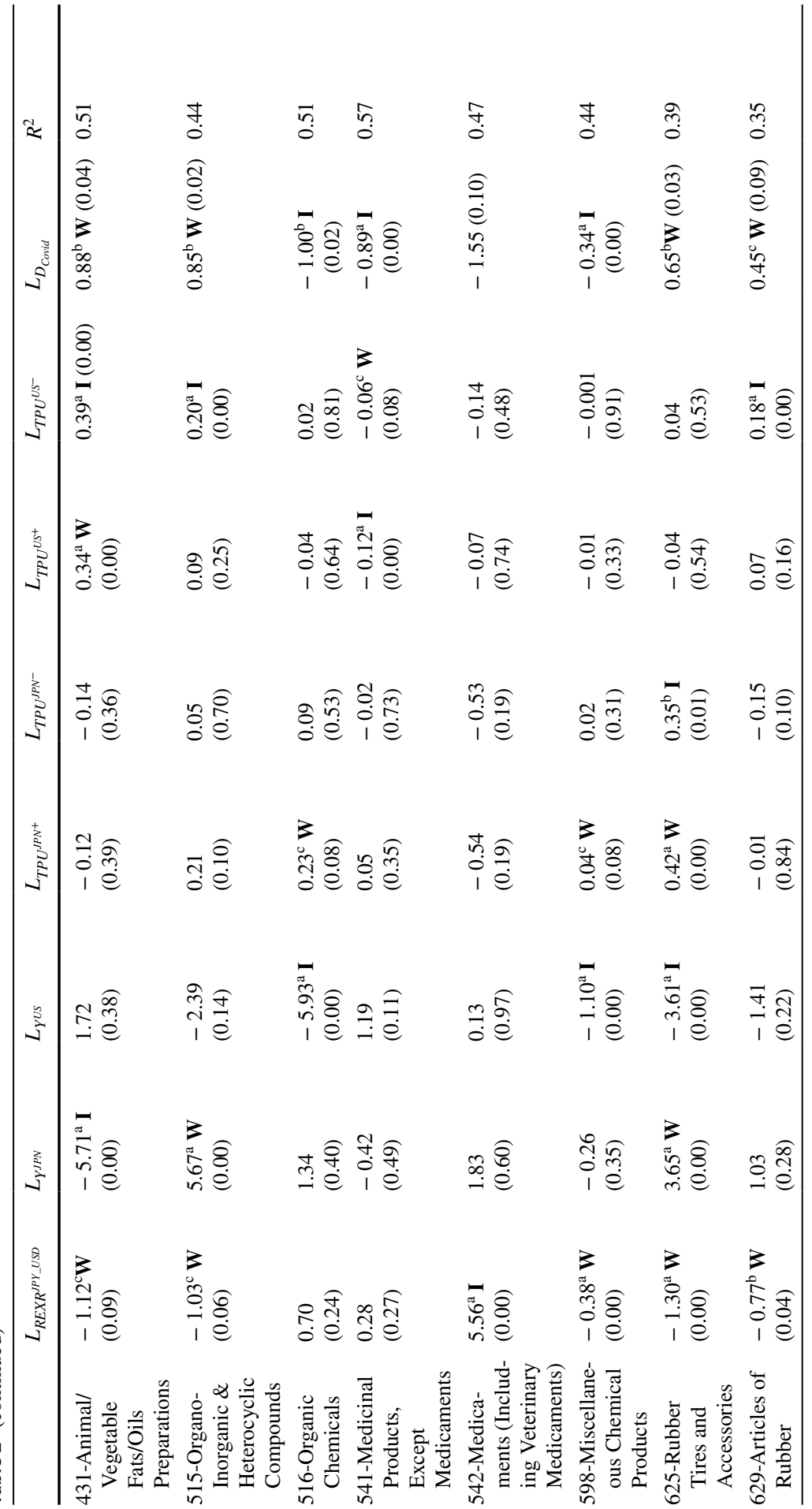




\begin{tabular}{|c|c|c|c|c|c|c|c|c|}
\hline$\approx$ & $\stackrel{\infty}{\dddot{m}}$ & $\stackrel{m}{0}$ & mे & $\stackrel{f}{\stackrel{J}{0}}$ & 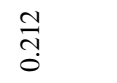 & $\stackrel{n}{q}$ & ஸे? & 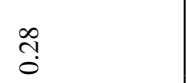 \\
\hline s. & $\begin{array}{l}\frac{\partial}{+} \\
e \\
\stackrel{n}{n} \\
0\end{array}$ & $\begin{array}{l}\widehat{\widehat{N}} \\
\stackrel{0}{0} \\
\infty \\
\vdots \\
0 \\
1\end{array}$ & 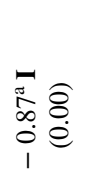 & $\begin{array}{l}\text { E. } \\
e \\
0 \\
0 \\
0 \\
\text { in }\end{array}$ & $\begin{array}{l}\text { fu} \\
\\
e \\
\text { त̂ } \\
0 \\
1\end{array}$ & 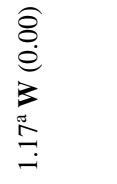 & $\begin{array}{l}\text { f } \\
\stackrel{f}{0} \\
0 \\
o \\
0 \\
0 \\
1\end{array}$ & $\begin{array}{l}80 \\
\dot{0} \\
1 \\
1\end{array}$ \\
\hline 永 & $\begin{array}{l}\hat{o} \\
\stackrel{+}{e} \\
\text { m } \\
\stackrel{0}{0}\end{array}$ & 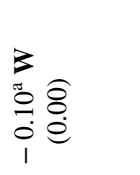 & 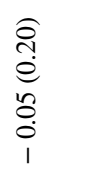 & $\begin{array}{l}\text { సิ } \\
\stackrel{e}{0} \\
\text { ڤ. }\end{array}$ & 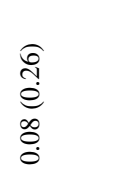 & 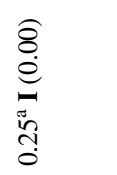 & 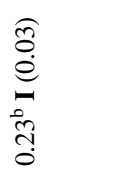 & $\begin{array}{l}\hat{\sigma} \\
\infty \\
e \\
0 \\
0 \\
0\end{array}$ \\
\hline 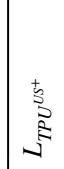 & $\begin{array}{l}\hat{\sigma} \\
\text { en } \\
e \\
\infty \\
\stackrel{1}{0}\end{array}$ & 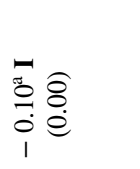 & $\begin{array}{l}\frac{0}{0} \\
0 \\
0 \\
0 \\
0 \\
0 \\
1\end{array}$ & 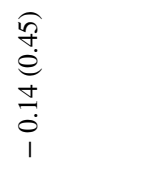 & $\begin{array}{l}0 \\
0 \\
\stackrel{0}{0} \\
0 \\
0 \\
0 \\
0 \\
1\end{array}$ & $\begin{array}{l}\hat{\sigma} \\
\tilde{0} \\
e \\
0 \\
0 \\
0\end{array}$ & $\begin{array}{l}a \\
0 \\
0 \\
a \\
0 \\
0\end{array}$ & 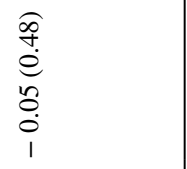 \\
\hline 竞 & 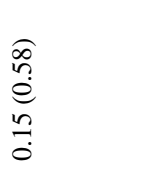 & $\begin{array}{l}\text { } \\
\stackrel{\infty}{+} \\
e \\
\stackrel{0}{0} \\
\stackrel{0}{0}\end{array}$ & 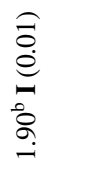 & $\begin{array}{l}\widehat{a} \\
\stackrel{0}{0} \\
0 \\
\vdots \\
0 \\
1\end{array}$ & $\begin{array}{l}\frac{n}{f} \\
e \\
0 \\
o \\
0 \\
0 \\
1\end{array}$ & $\begin{array}{l}\hat{a} \\
\stackrel{d}{0} \\
\vdots \\
0 \\
0\end{array}$ & 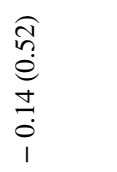 & $\begin{array}{l}\text { Õ } \\
\stackrel{0}{0} \\
0 \\
0 \\
0 \\
1\end{array}$ \\
\hline 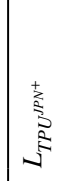 & $\begin{array}{l}\hat{E} \\
\stackrel{0}{e} \\
\vdots \\
0 \\
0\end{array}$ & $\begin{array}{l}\frac{1}{5} \\
f \\
e \\
\pm \\
0 \\
0\end{array}$ & 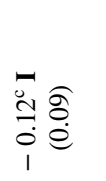 & 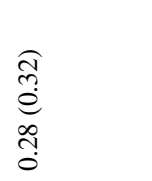 & 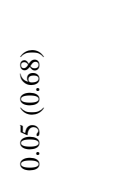 & 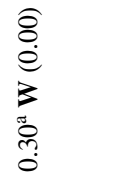 & $\begin{array}{l}\hat{2} \\
\stackrel{0}{0} \\
o \\
0 \\
0 \\
1 \\
1\end{array}$ & 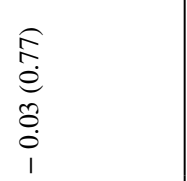 \\
\hline$\stackrel{3}{3}$ & 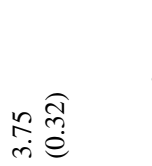 & $\begin{array}{l}\vec{y} \\
\stackrel{0}{0} \\
\stackrel{0}{0} \\
\end{array}$ & 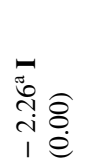 & 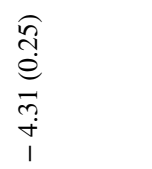 & 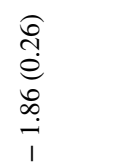 & $\begin{array}{l}\widehat{a} \\
\text { è } \\
\pm \\
\vdots \\
1\end{array}$ & $\begin{array}{l}\hat{\imath} \\
\text { iิ } \\
1\end{array}$ & 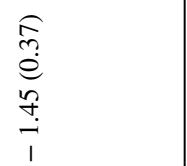 \\
\hline 녹 & 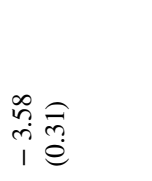 & 을 & 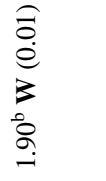 & $\begin{array}{l}\text { I } \\
\stackrel{0}{e} \\
\vdots \\
i \\
\text { in }\end{array}$ & $\stackrel{\overbrace{}}{\stackrel{f}{m}}$ & $\begin{array}{l}\text { f } \\
\stackrel{f}{e} \\
0 \\
0 \\
0 \\
0 \\
1\end{array}$ & 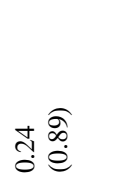 & 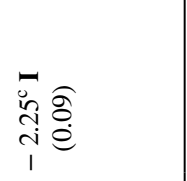 \\
\hline 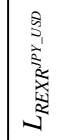 & 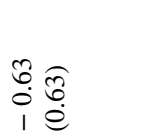 & $=\frac{\sqrt[6]{0}}{0}$ & 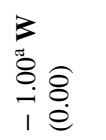 & 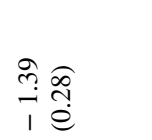 & $\begin{array}{l}\hat{n} \\
\hat{0} \\
1 \stackrel{n}{e}\end{array}$ & 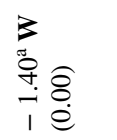 & 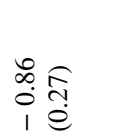 & 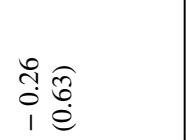 \\
\hline & 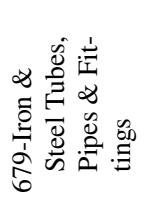 & 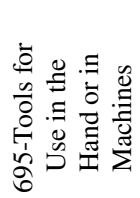 & 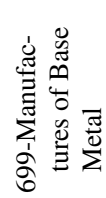 & 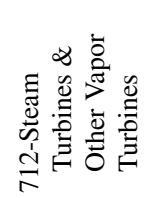 & 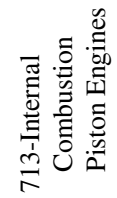 & 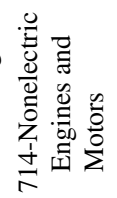 & 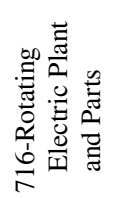 & 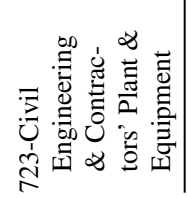 \\
\hline
\end{tabular}




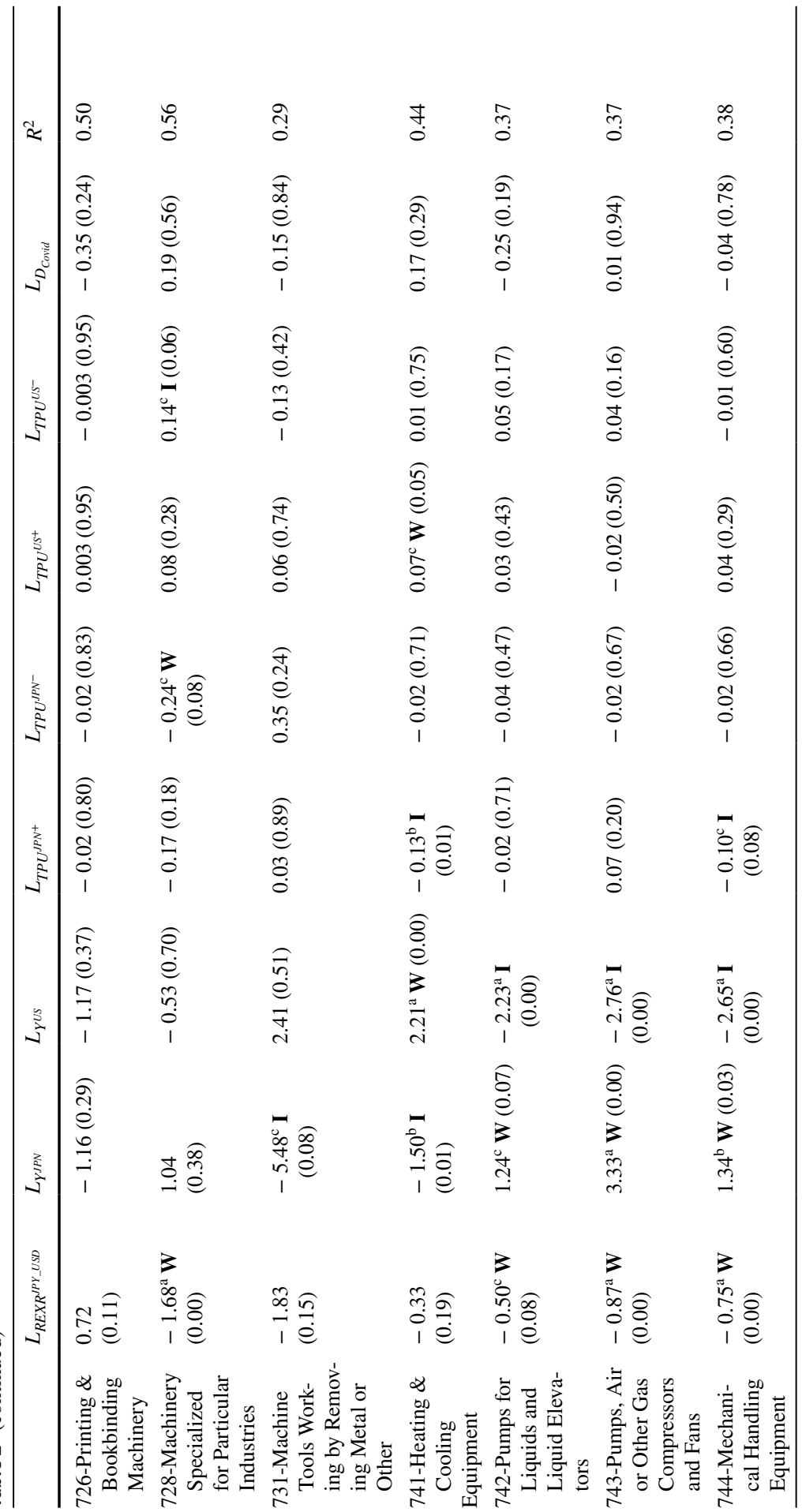




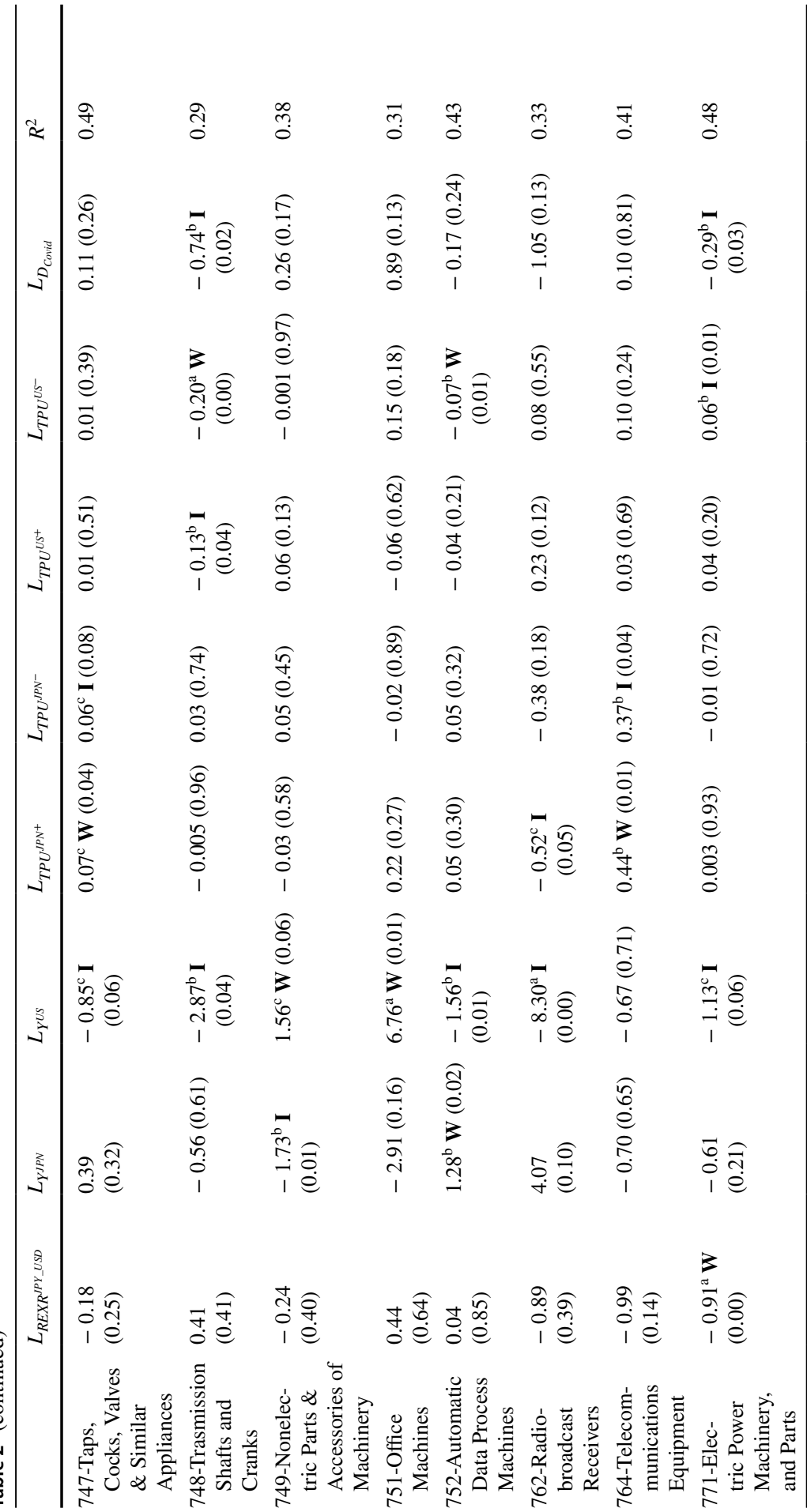




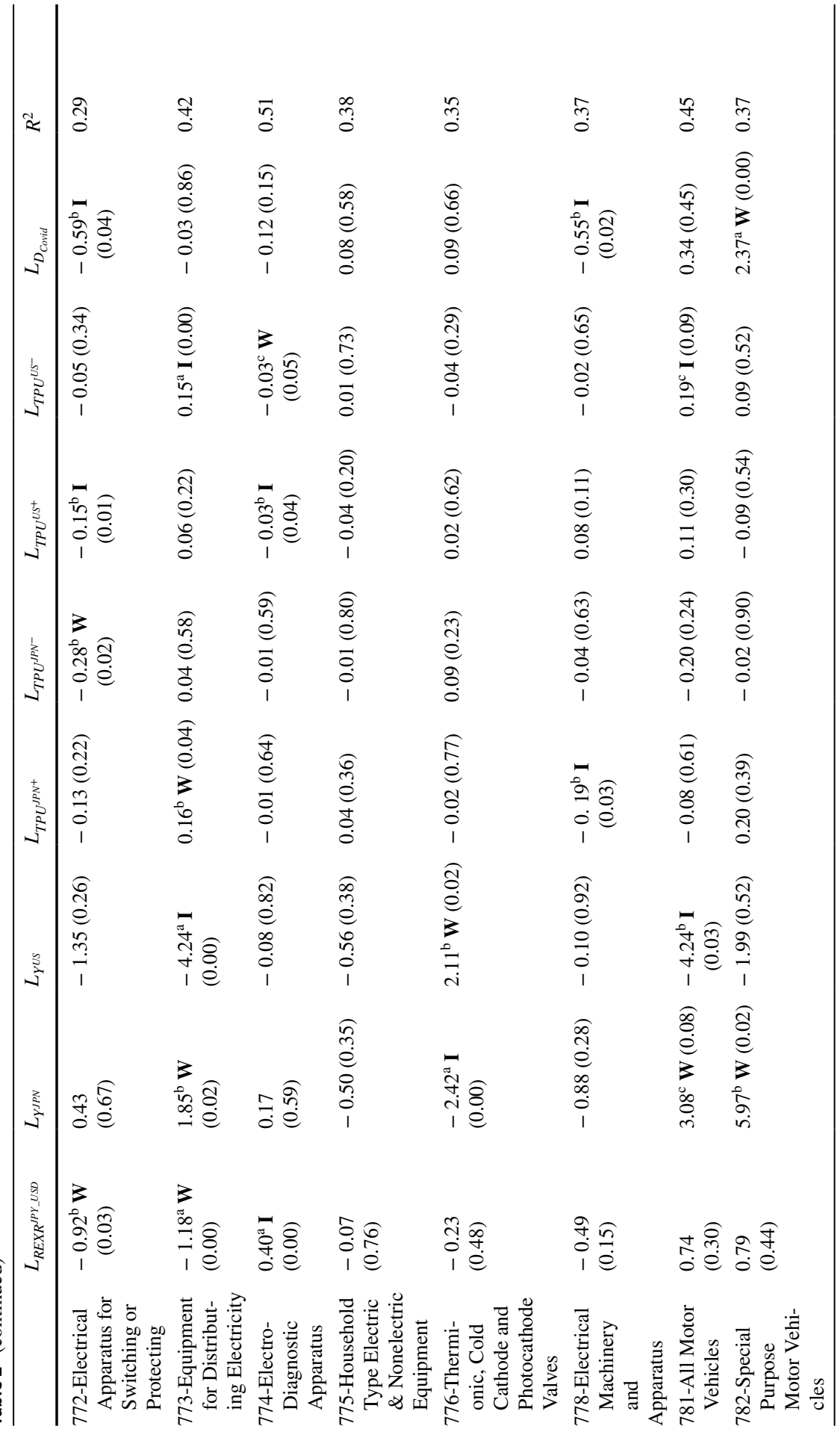




\begin{tabular}{|c|c|c|c|c|c|c|c|c|}
\hline 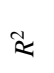 & $\stackrel{\infty}{\stackrel{\infty}{0}}$ & ָे & ले & $\stackrel{?}{+}$ & $\stackrel{f}{+}$ & $\stackrel{n}{n}$ & $\hat{\tilde{y}}$ & $\stackrel{?}{\stackrel{0}{0}}$ \\
\hline 每 & 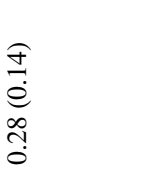 & 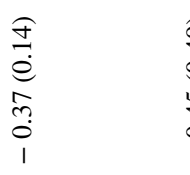 & 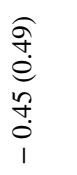 & $\begin{array}{l}\hat{\sigma} \\
\stackrel{0}{0} \\
\infty \\
0 \\
0 \\
1 \\
1\end{array}$ & $\begin{array}{l}\text { I } \\
\stackrel{0}{0} \\
0 \\
\infty \\
0 \\
1\end{array}$ & $\begin{array}{l}\text { f } \\
\text { ê } \\
\text { - } \\
0 \\
1\end{array}$ & $\begin{array}{l}\hat{\sigma} \\
\hat{e} \\
n \\
\frac{1}{0} \\
1\end{array}$ & 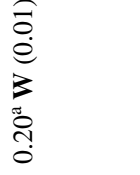 \\
\hline 离 & $\begin{array}{l}\widehat{\delta} \\
\dot{\theta} \\
0 \\
0 \\
0 \\
0\end{array}$ & $\begin{array}{l}3 \\
0 \\
0 \\
0 \\
0 \\
1\end{array}$ & 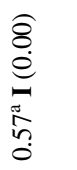 & $\begin{array}{l}\hat{2} \\
e \\
e \\
0 \\
0 \\
0 \\
1\end{array}$ & 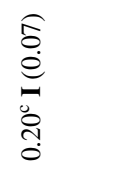 & 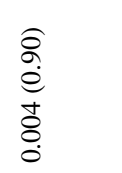 & 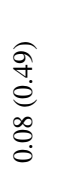 & 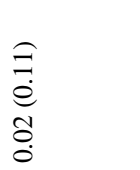 \\
\hline 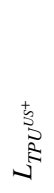 & 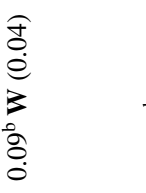 & 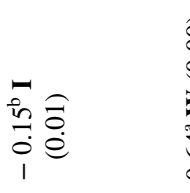 & $\begin{array}{l}\hat{8} \\
e \\
e \\
3 \\
0 \\
0 \\
0 \\
0\end{array}$ & 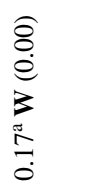 & 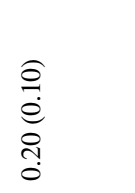 & 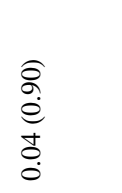 & 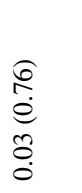 & $\begin{array}{l}\sigma \\
0 \\
e \\
e \\
o \\
0\end{array}$ \\
\hline \begin{tabular}{l}
$\frac{1}{2}$ \\
\multirow{3}{3}{} \\
\multirow{3}{*}{}
\end{tabular} & $\begin{array}{l}0 \\
0 \\
+ \\
e \\
e \\
o \\
0 \\
0 \\
1\end{array}$ & $\begin{array}{l}\stackrel{\jmath}{ \pm} \\
\stackrel{0}{0} \\
m \\
\stackrel{0}{0}\end{array}$ & 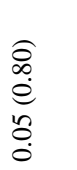 & $\begin{array}{l}0 \\
\infty \\
0 \\
e \\
0 \\
0 \\
0 \\
1\end{array}$ & 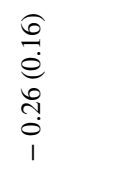 & $\begin{array}{l}0 \\
0 \\
0 \\
0 \\
0 \\
0 \\
0 \\
1\end{array}$ & 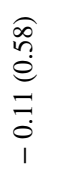 & 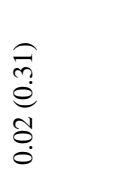 \\
\hline 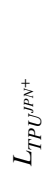 & $\begin{array}{l}\hat{2} \\
\dot{a} \\
\dot{e} \\
0 \\
\dot{0}\end{array}$ & 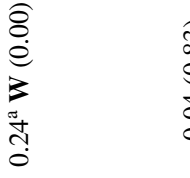 & $\begin{array}{l}\widehat{\hat{O}} \\
\infty \\
0 \\
\dot{0} \\
\dot{0} \\
\dot{0} \\
1\end{array}$ & 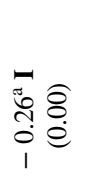 & 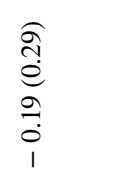 & $\begin{array}{l}\text { E } \\
0 \\
0 \\
\vdots \\
0 \\
1\end{array}$ & $\begin{array}{l}\hat{2} \\
\hat{e} \\
e \\
o \\
0 \\
1\end{array}$ & 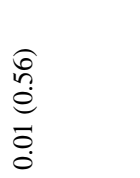 \\
\hline 3 & 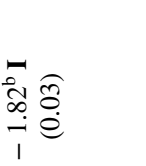 & 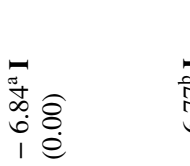 & 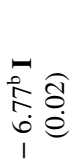 & $\begin{array}{l}\widehat{0} \\
0 \\
\stackrel{0}{0} \\
\vdots \\
0\end{array}$ & 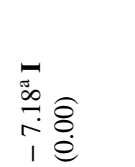 & $\begin{array}{l}\widehat{\Xi} \\
\dot{e} \\
\dot{e} \\
0 \\
\dot{0} \\
1\end{array}$ & 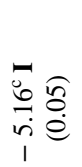 & 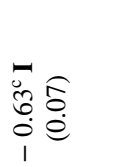 \\
\hline 交 & 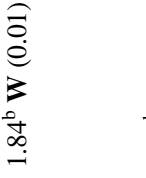 & 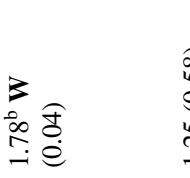 & 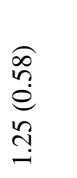 & $\begin{array}{l}\text { E़ } \\
e \\
\stackrel{0}{0} \\
\stackrel{i}{0} \\
1\end{array}$ & 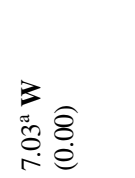 & $\begin{array}{ll}\infty & \frac{n}{2} \\
0 & \stackrel{0}{e}\end{array}$ & 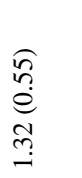 & $\begin{array}{l}\hat{\sigma} \\
\hat{n} \\
e \\
0 \\
0 \\
0\end{array}$ \\
\hline 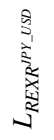 & 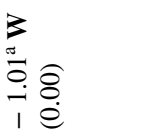 & 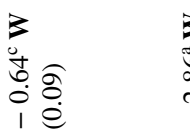 & 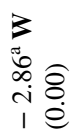 & 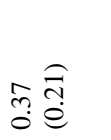 & 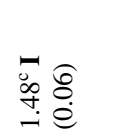 & 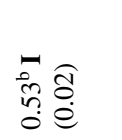 & 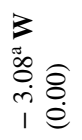 & 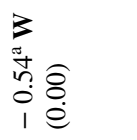 \\
\hline & 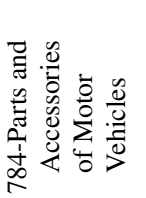 & 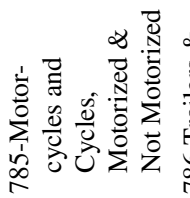 & 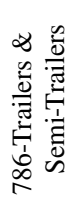 & 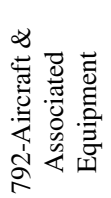 & 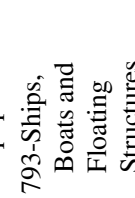 & 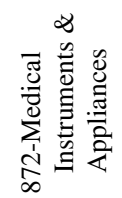 & 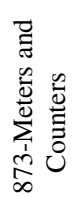 & 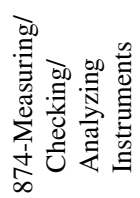 \\
\hline
\end{tabular}




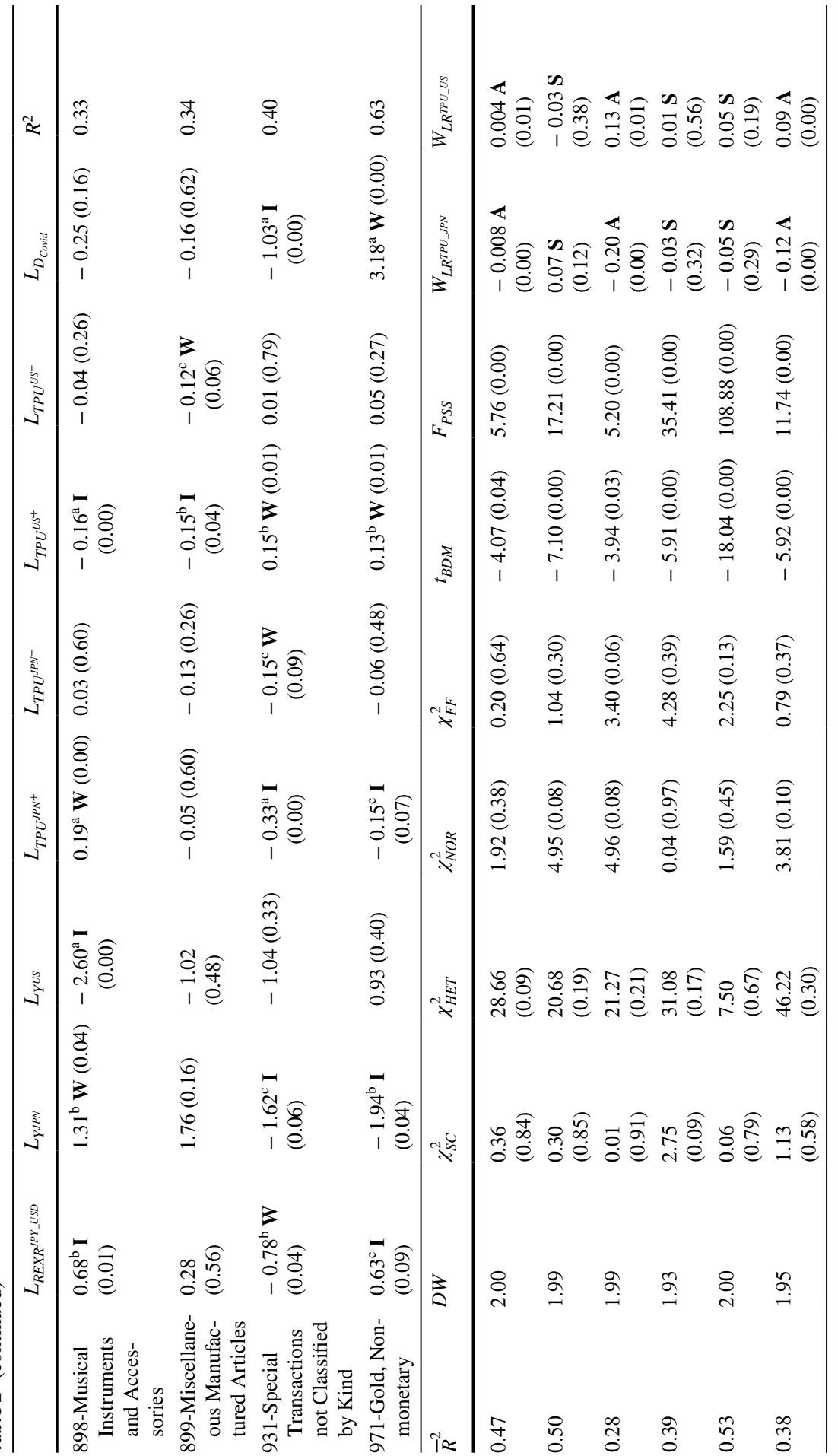




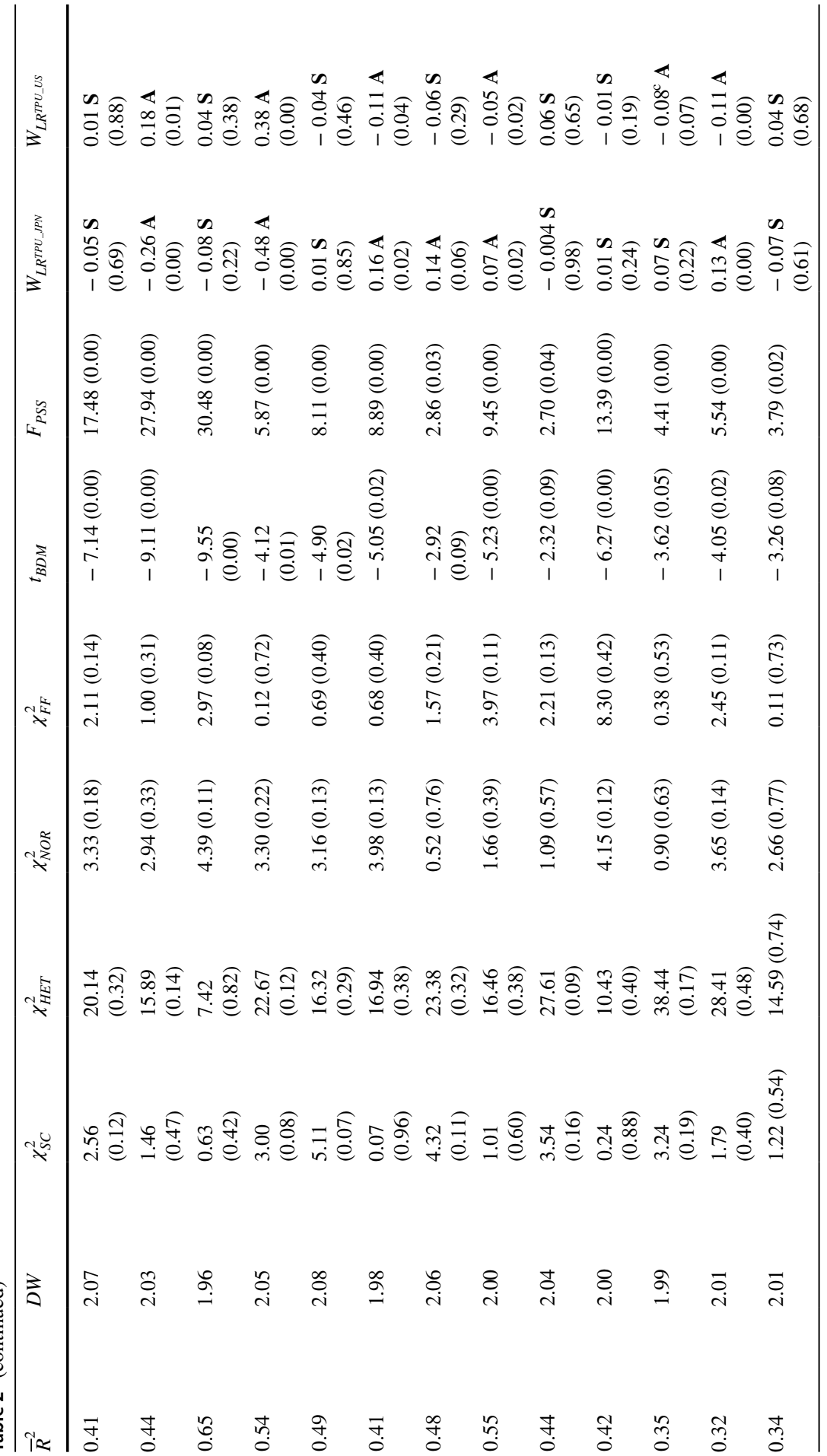




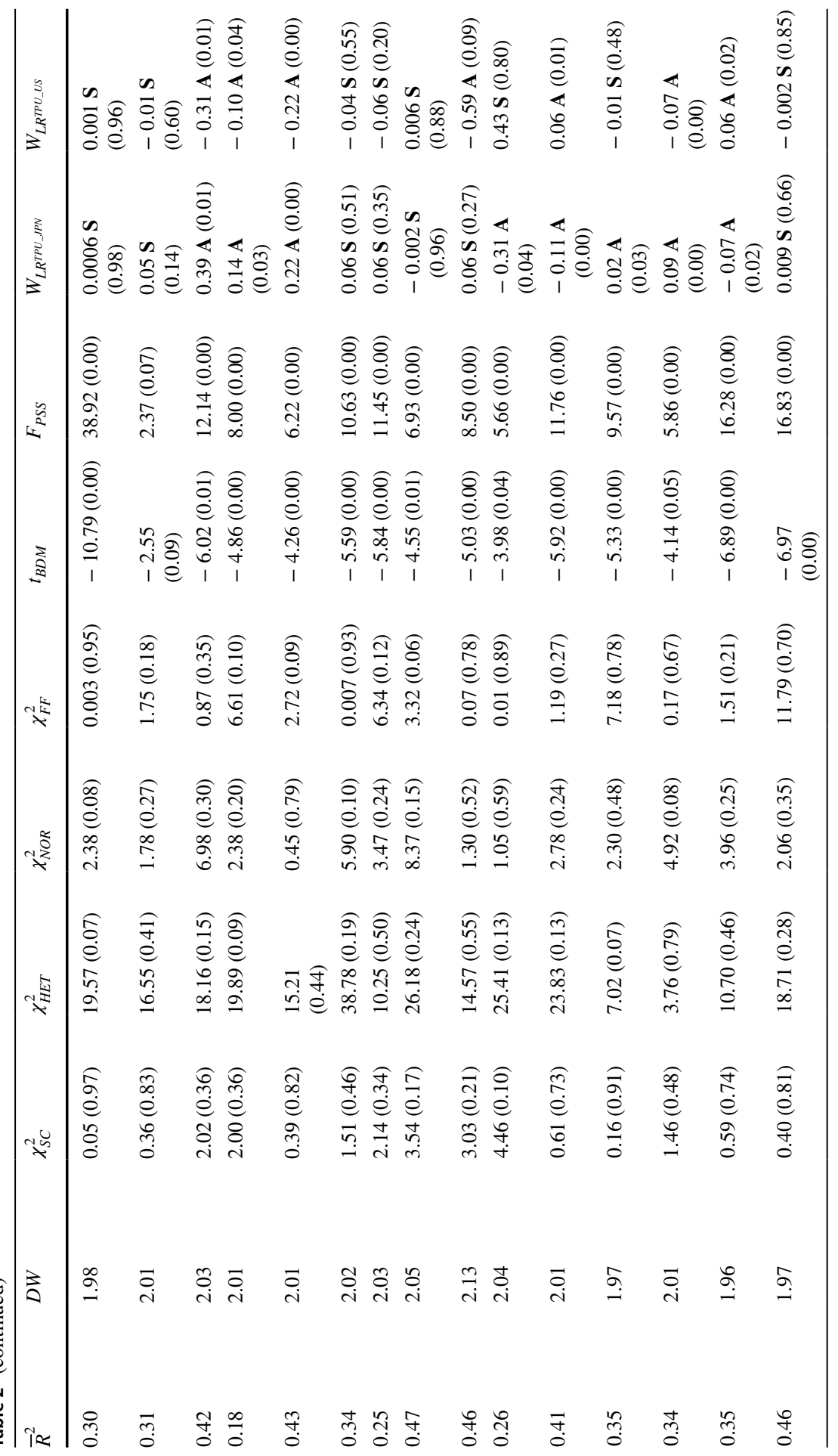




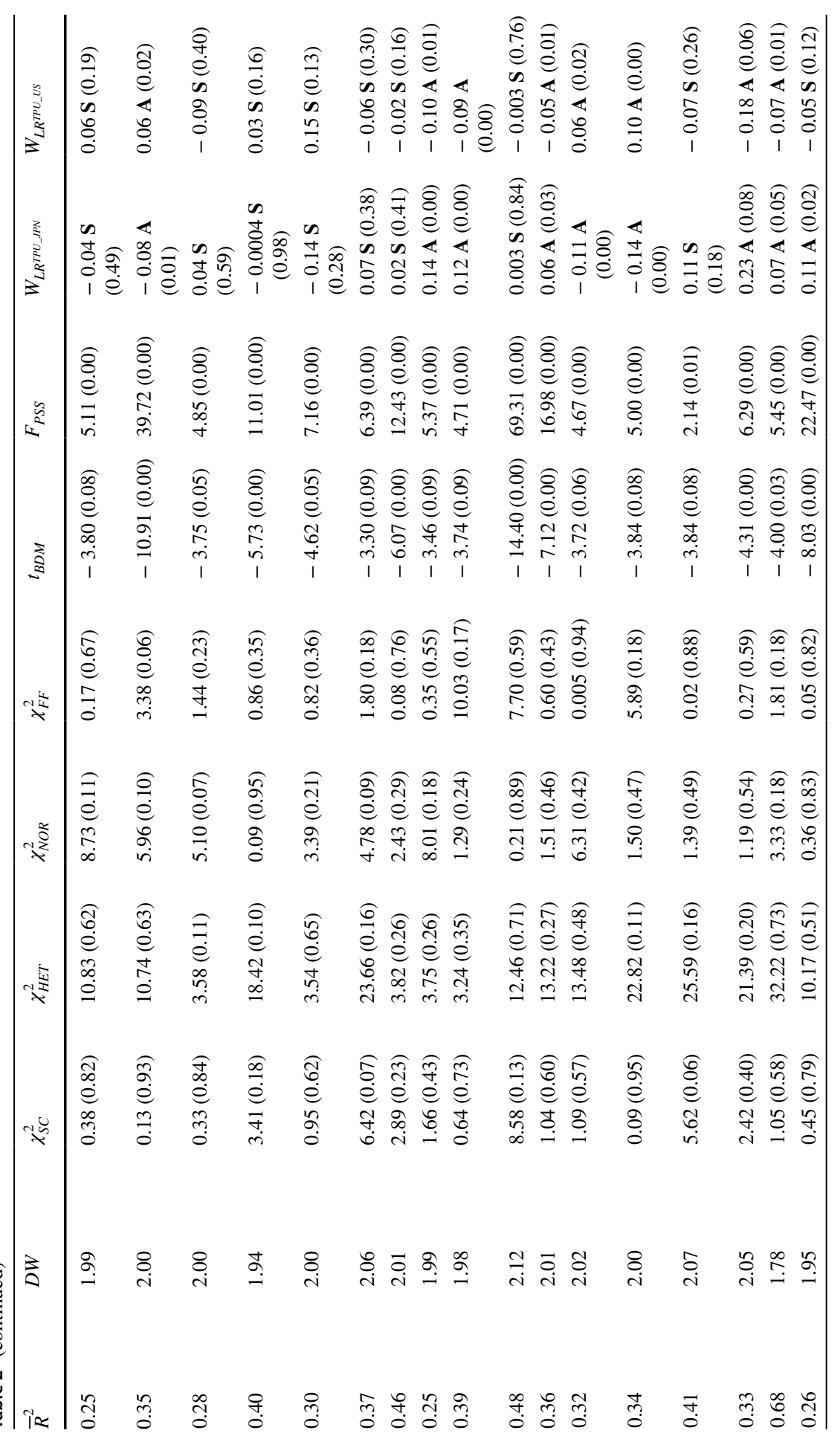




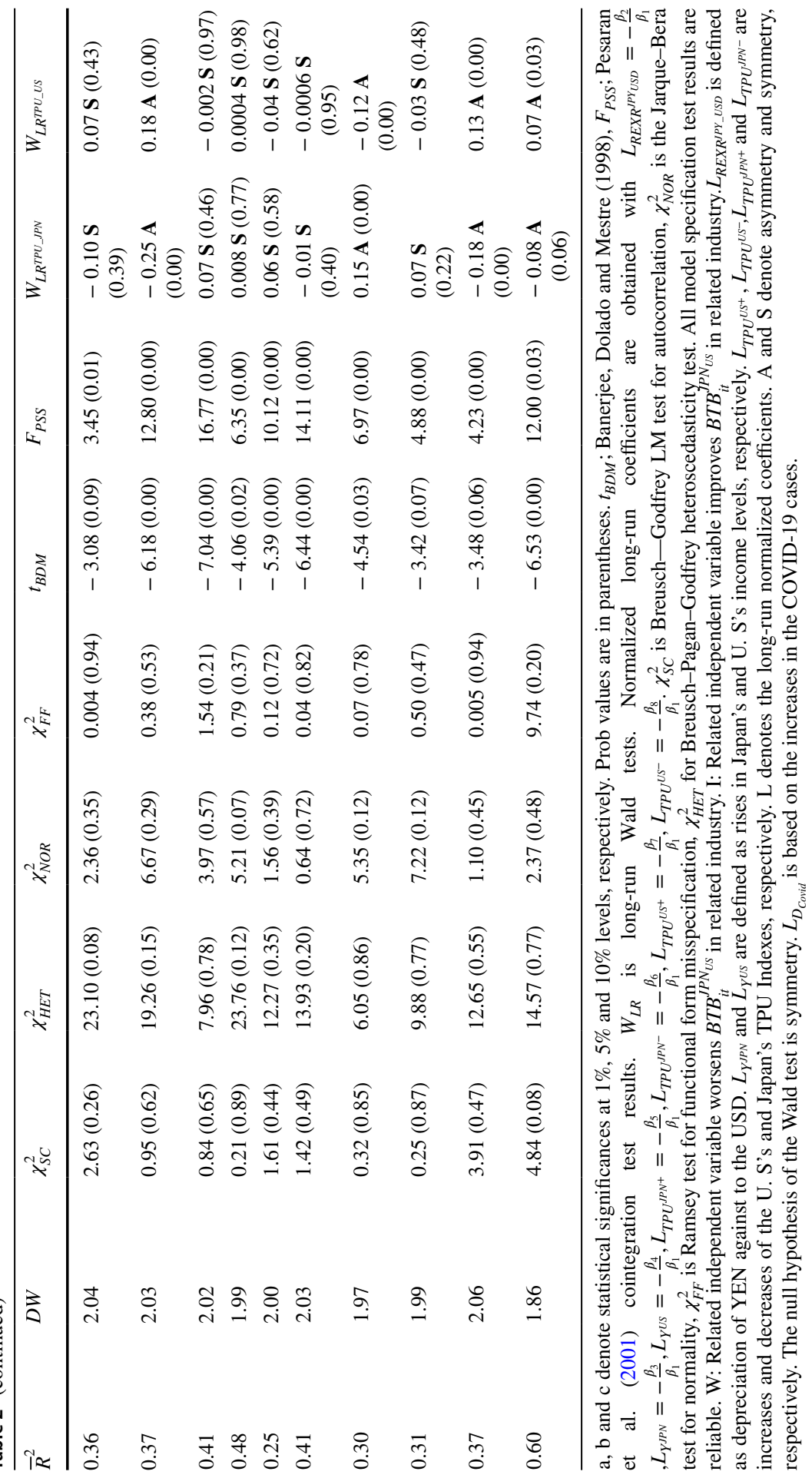


model finds that changes in exchange rates worsen and improve this balance for 22 and 7 industries, respectively. Similarly, while the aggregated data model finds no impact of rises in Japan's income $\left(Y_{t}^{J P N}\right)$ on $\mathrm{BTB}_{i t}^{J P N_{-} U S}$, the disaggregated data model finds that rises in $Y_{t}^{J P N}$ worsen and improve this balance for 18 and 10 industries, respectively. While the aggregated data model finds that rises in US income $\left(Y_{t}^{U S}\right)$ improve this balance, the disaggregated data model finds that rises in $Y_{t}^{U S}$ worsen this balance for 5 industries. Moreover, while the aggregated data model finds that rises in Japan's TPU index $\left(\mathrm{TPU}_{t}^{J P N^{+}}\right)$worsen $\mathrm{BTB}_{i t}^{J P N}{ }^{U S}$, the disaggregated data model finds that rises in this index improve this balance for 11 industries. Similarly, while the aggregated data model finds that falls in Japan's TPU index $\left(\mathrm{TPU}_{t}^{J P N^{-}}\right.$) improve $\mathrm{BTB}_{i t}^{J P N_{-} U S}$, the disaggregated data model finds that these falls worsen this balance for 5 industries. This is the same for US TPU indexes. While the aggregated data model finds that rises in the US TPU index $\left(\mathrm{TPU}_{t}^{U S^{+}}\right)$improve $\mathrm{BTB}_{i t}^{J P N_{-} U S}$, the disaggregated data model finds that such rises worsen this balance for 8 industries. Similarly, while the aggregated data model finds that falls in $\mathrm{TPU}_{t}^{U S^{-}}$worsen $\mathrm{BTB}_{i t}^{J P N_{-} U S}$, the disaggregated data model finds that such falls improve this balance for 14 industries. Similarly, while aggregated data model finds no impacts of the COVID-19 on $\mathrm{BTB}_{i t}^{J P N_{-} U S}$, the disaggregated data finds that this pandemic worsens this balance for 10 industries coded 334, $431,515,625,629,712,714,782,874$, and 971 .

Based on the behaviors of Japanese consumers, through their import demands, it can be interpreted that they are not uncertainty-sensitive to US products coded 516, 598, 625, 714, 747, 764, 773, 785, and 898, while Japan's TPU index rises. However, they are uncertainty-sensitive to US products coded 081, 411, 699, 741, 744, 762, 778, 792, 931, and 971, while Japan's TPU index rises. This can be interpreted that Japan continues to import mainly inelastic US products such as organic chemicals (516), miscellaneous chemical products (598), and telecommunication equipment that are used as intermediate goods in this country. Similarly, Japan does not import mainly elastic US products such as feeding stuff for animals (081), animal oils and fats (411), and gold, nonmonetary (971). In the same vein, US consumers are uncertainty-sensitive to Japanese products coded 232, 431, 741, 784, 786, 792, 931, and 971, while the US TPU index rises. However, they are not uncertaintysensitive to Japanese products coded 111, 421, 541, 695, 748, 772, 774, 785, 898, and 899, while the US TPU index rises.

In the evaluation of overall test results in Table 2, we could not find any impact of either the US TPU index or Japan's TPU index on Japan's bilateral trade balance with the U.S $\left(\mathrm{BTB}_{i t}^{J P N_{-} U S}\right)$ for 18 out of 60 industries. Furthermore, both rises and falls in Japan's TPU index (TPU ${ }_{t}^{J P N^{+}}$, TPU ${ }_{t}^{J P N^{-}}$) have significant improving or worsening impacts on this balance for a total of 30 industries. Similarly, both rises and falls in the US TPU index (TPU ${ }_{t}^{U S^{+}}$, TPU ${ }_{t}^{U S^{-}}$) have significant improving or worsening impacts on this balance for a total of 24 industries. In the comparison of US and Japan's TPU indexes, this can be interpreted as meaning that the impacts of Japan's TPU index on this balance are higher than those of the US TPU index.

For the sake of economy, the determination of symmetry and asymmetry by the Wald test will be explained for only one industry, namely the one coded 781. While rises $\left(\mathrm{TPU}_{t}^{J P N^{+}}\right)$and falls (TPU ${ }_{t}^{J P N^{-}}$) in Japan's TPU index have different magnitude 
and different direction impacts (which denotes asymmetry) on $\mathrm{BTB}_{i t}^{J P N_{-} U S}$, rises $\left(\mathrm{TPU}_{t}^{U S^{+}}\right)$and falls $\left(\mathrm{TPU}_{t}^{U S^{-}}\right)$in the US TPU index have the same magnitude and same direction impacts (which denotes Symmetry) on it. The equations of $-\beta_{5} / \beta_{1}=-\beta_{6} / \beta_{1}$ and $-\beta_{7} / \beta_{1} \neq-\beta_{8} / \beta_{1}$ correspond to symmetry and asymmetry, respectively.

\section{Conclusion}

This study examines potential impacts of Japan's and US trade policy-related uncertainties, scaled by TPU indexes, on Japan's bilateral trade balance with the U.S concerning 60 industries. Furthermore, this study also considers-examines the impacts of the COVID-19 pandemic on this country's trade balance. The rationale of this consideration is based on that international trade volumes can be highly and directly affected by such a big pandemic. In this examination, we assume that aggregated trade data may conceal the true existing relations between this balance (dependent variable) and TPU indexes (independent variables) in our model. In order to discover such potentially existing relations and avoid this aggregation bias, we use disaggregated data. We also assume that increases and decreases in both countries' TPU indexes, considered separately, may have different (nonlinear) impacts on Japan's bilateral trade balance with the U.S. In order to examine these separate impacts, we apply the nonlinear ARDL model, which technically enables such a separation. Empirical findings of this study strongly verify that our assumptions are true. The disaggregated data model clearly finds which independent variable in which industry improves or worsens this balance aggregated data cannot find. Furthermore, the nonlinear model clearly reveals different impacts of increases or decreases of TPU indexes on this balance.

The main empirical finding of this study is that trade policy-related uncertainties of both countries (TPU indexes) have significant impacts on Japan's bilateral trade balance for 42 out of 60 industries, improving or worsening this balance (shown in Table 2). Additionally, based on the behaviors of Japanese and US consumers, through their import demands, it can be interpreted that Japanese consumers are not uncertainty-sensitive to US products and they continue to buy these products even Japan's TPU index keeps rising. Similarly, US consumers are also not uncertainty-sensitive to Japanese products and they continue to buy these products even the US TPU index keeps rising (findings from the aggregated data model). Another expected finding is that the COVID-19 pandemic worsens the trade balance of Japan for different industries such as oil (not crude), rubber tires and accessories, nonelectric engines and motors, special purpose motor vehicles, and organo-inorganic-heterocyclic compounds. This can be interpreted that Japan is not the COVID-19-sensitive to mainly inelastic US products.

We believe that the overall findings of this study will provide both countries' policymakers with crucial information about how each industry responds to changing trade policy uncertainties and pandemics. Hence, they will be able to create individual industry-level uncertainty-sensitivity and the COVID-19 affected maps-tables, 
which will help them manage their bilateral trade balances proactively. In this context, the findings of this study indicate the need for future empirical studies concerning other countries for having such maps-tables globally and bilaterally.

\section{Declarations}

Conflict of interest The authors declare that there is no conflict of interest regarding the publication of this article.

\section{References}

Adedoyin FF, Afolabi JO, Yalciner K, Bekun FV (2020) The export-led growth in Malaysia: Does economic policy uncertainty and geopolitical risks matter? J Public Affairs. https://doi.org/10.1002/pa. 2361

Arbatli, EC, Davis SJ, Ito A, Miake N (2019) Policy uncertainty in Japan. NBER Working Paper, No. 23411

Ashraf BN, Shen Y (2019) Economic policy uncertainty and banks' loan pricing. J Financ Stab 44(C):1-37

Bahmani-Oskooee M, Brooks TJ (1999) Bilateral J-curve between US and her trading partners. Weltwirtschaftliches Archiv 135(1):156-165

Bahmani-Oskooee M, Nayeri MM (2020) Policy uncertainty and the demand for money in the United Kingdom: are the effects asymmetric? Econ Anal Policy 66(C):76-84

Baker SR, Bloom S, Davis SJ (2016) Measuring economic policy uncertainty. Q J Econ 13(4):1593-1636

Beckmann J, Czudaj R (2017) Exchange rate expectations and economic policy uncertainty. Eur J Polit Econ 47(C):148-162

Census Bureau (2020) The United States Census Bureau, Country and Product Trade Data https://www. census.gov/foreign-trade/statistics/country/index.html

Caldara D, Iacoviello M, Molligo P, Prestipino A, Raffo A (2020) The economic effects of trade policy uncertainty. J Monet Econ 109(C):38-59

Canh NP, Binh NT, Thanh S, Schinckus C (2020) Determinants of foreign direct investment inflows: the role of economic policy uncertainty. Int Econ 161:159-172

Chen X, Chiang TC (2020) Empirical investigation of changes in policy uncertainty on stock returnsevidence from China's market. Res Int Bus Financ 53:101-183

Čižmešija M, Lolić I, Sorić P (2017) Economic policy uncertainty index and economic activity: what causes what?". Croat Oper Res Rev 8(2):563-575

Constantinescu C, Mattoo A, Ruta M (2015) The Global Trade Slowdown: cyclical or Structural?" World Bank Policy Research Working Paper, No. 7158. Washington, DC

Davis SJ, Liu D, Sheng XS (2019) Economic Policy Uncertainty in China Since 1949: the view from Mainland newspapers. Fourth Annual IMF-Atlanta Fed Research Workshop on China's Economy Atlanta, 19 September

Demir E, Gozgor G, Lau CKM, Vigne SA (2018) Does economic policy uncertainty predict the Bitcoin returns? an empirical investigation. Financ Res Lett 26(C):145-149

Ghirelli C, Pérez JJ, Urtasun A (2019) A new economic policy uncertainty index for Spain. Econ Lett 182:64-67

Han L, Qi M, Yin L (2016) Macroeconomic policy uncertainty shocks on the Chinese economy: a GVAR analysis. Appl Econ 48(51):4907-4921

Haynes SE, Stone JA (1982) Impact of the terms of trade on the US trade balance a reexamination. Rev Econ Stat 64(4):702-706

Hsieh HC, Chi BS, Vu TH (2019) The effects of economic policy uncertainty on outward foreign direct investment. Int Rev Econ Financ 64(C):377-392

Huang Y, Luk P (2020) Measuring economic policy uncertainty in China. China Econ Rev 59(C):1013-1067 
Ivanovski K, Churchill SA (2019) Economic policy uncertainty and demand for money in Australia. Appl Econ 51(41):4516-4526

Jia F, Huang X, Xu X, Sun H (2020) The effects of economic policy uncertainty on export: a gravity model approach. Prague Econ Pap Prague Univ Econ Bus 5:600-622

Li XM, Zhang B, Gao R (2015) Economic policy uncertainty shocks and stock-bond correlations: evidence from the US market. Econ Lett 132:91-96

Liming C, Ziqing D, Zhihao H (2020) Impact of economic policy uncertainty on exchange rate volatility of China. Financ Res Lett 32(C):1-5

Pesaran MH, Pesaran B (1997) Working with Microfit 4.0: interactive econometric analysis. Oxford University Press, Oxford

Pesaran M, Shin Y, Smith RJ (2001) Bounds testing approaches to the analysis of level relationships. J Appl Economet 16(3):289-326

Shin Y, Yu B, Greenwood-Nimmo M (2014) Modelling asymmetric cointegration and dynamic multipliers in a nonlinear ARDL framework. In: Sickels R, Horrace W (eds) Festschrift in honor of peter schmidt: econometric methods and applications. Springer, New Yorkpp, pp 281-314

Shin M, Zhang B, Zhong M, Lee J (2018) Measuring international uncertainty: the case of Korea. Econ Lett 162:22-26

Tam Sun P (2018) Global trade flows and economic policy uncertainty. Appl Econ 50(34-35):3718-3734

Wang P, Li X, Shen D, Zhang W (2020) How does economic policy uncertainty affect the bitcoin market? Res Int Bus Financ 53(C):101234

Wei Y (2019) Oil price shocks, economic policy uncertainty and China's trade: a quantitative structural analysis. North Am J Econ Financ 48(C):20-31

Yin DAI, Zhang J, Yu XZ, Xin LI (2017) Causality between economic policy uncertainty and exchange rate in China with considering quantile differences. Theor Appl Econ 24:29-38

Publisher's Note Springer Nature remains neutral with regard to jurisdictional claims in published maps and institutional affiliations. 